\title{
Improving WRF-Hydro Runoff Predictions of Heavy Floods Through Higher Spatio-Temporal Sea Surface Temperature Products
}

\author{
Berina Kilicarslan ${ }^{1}$, ismail yucel ${ }^{1}$, Heves Pilatin ${ }^{1}$, Eren Duzenli ${ }^{1}$, and Mustafa Yllmaz ${ }^{2}$ \\ ${ }^{1}$ Middle East Technical University \\ ${ }^{2}$ Orta Dogu Teknik Universitesi
}

February 8, 2021

\begin{abstract}
In this study, the impact of spatio-temporal accuracy of four different sea surface temperature (SST) datasets on the accuracy of the Weather Research and Forecasting (WRF)-Hydro system to simulate hydrological response during two catastrophic flood events over Eastern Black Sea (EBS) and Mediterranean (MED) regions of Turkey is investigated. Three time-varying and high spatial resolution external SST products (GHRSST, Medspiration, and NCEP-SST) and one coarse-resolution and invariable SST product (ERA5- and GFS-SST for EBS and MED regions, respectively) already embedded in the initial and boundary condition dataset of WRF model are used in deriving near-surface weather variables through WRF. After the proper eventbased calibration performed to the WRF-Hydro using hourly and daily streamflow data of small catchments in both regions, uncoupled model simulations for independent SST events are conducted to assess the impact of SST-triggered precipitation on simulated extreme runoff. Some localized and temporal differences in the occurrence of the flood events with respect to observations depending on the SST representation are noticeable. SST products represented with higher temporal and spatial correlation revealed significant improvement in flood hydrographs for both regions. The higher spatial and temporal correlations of GHRSST dataset show RMSE reduction up to $20 \%$ and increase in correlation from 0.3 to 0.8 with respect to the invariable SST (ERA5) in simulated runoffs over the EBS region. The error reduction with GHRSST reached $35 \%$ after the calibration of hydrological model parameters compared to not calibrated model. The use of both GHRSST and Medspiration SST data characterized with high spatiotemporal correlation resulted in runoff simulations exactly matching the observed runoff peak of $300 \mathrm{~m} 3 / \mathrm{s}$ by reducing the overestimation seen in not calibrated runs over the MED region.
\end{abstract}

\section{Hosted file}

Main_Document.pdf available at https://authorea.com/users/388828/articles/507832-improvingwrf-hydro-runoff-predictions-of-heavy-floods-through-higher-spatio-temporal-sea-surfacetemperature-products 

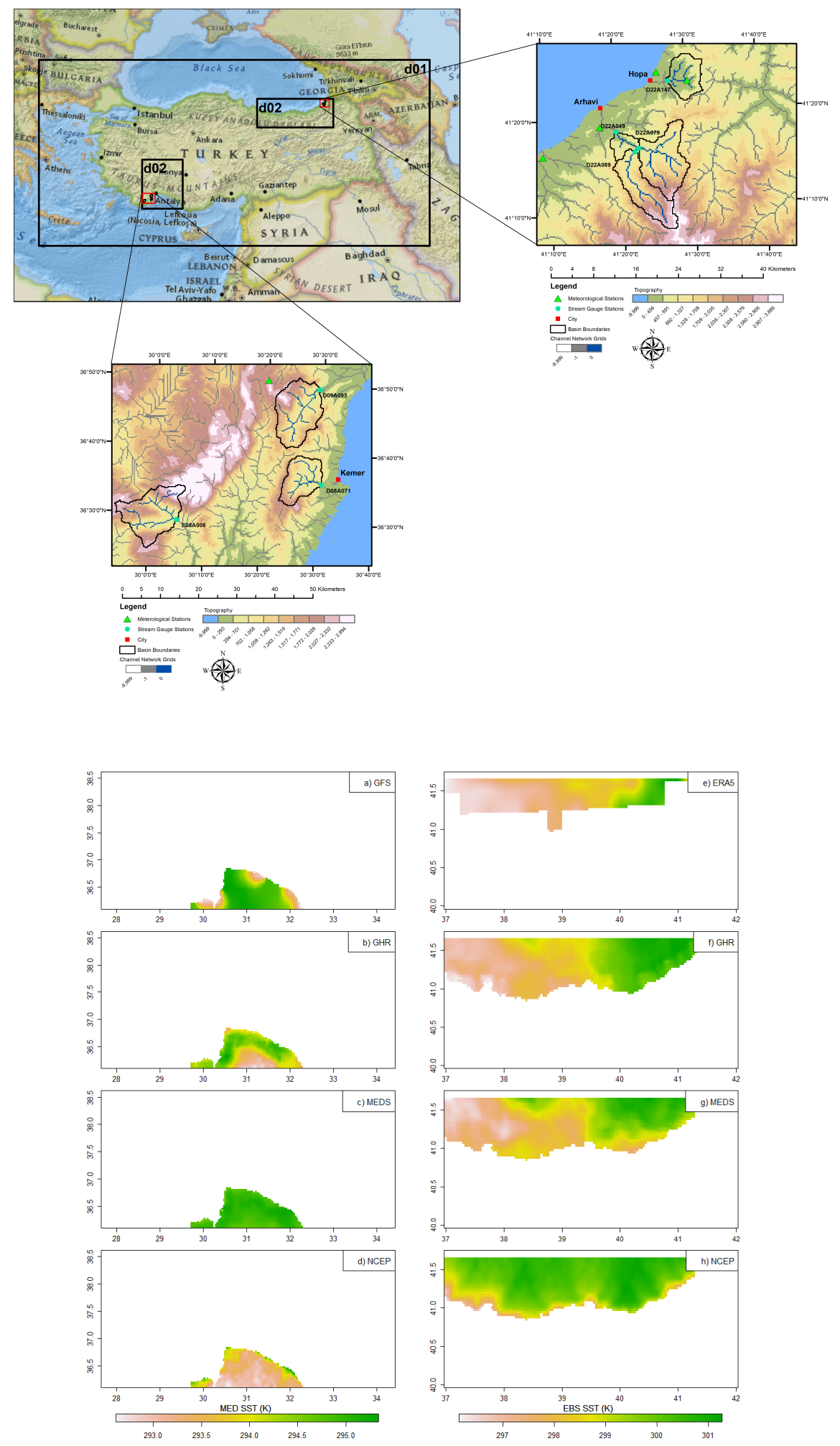


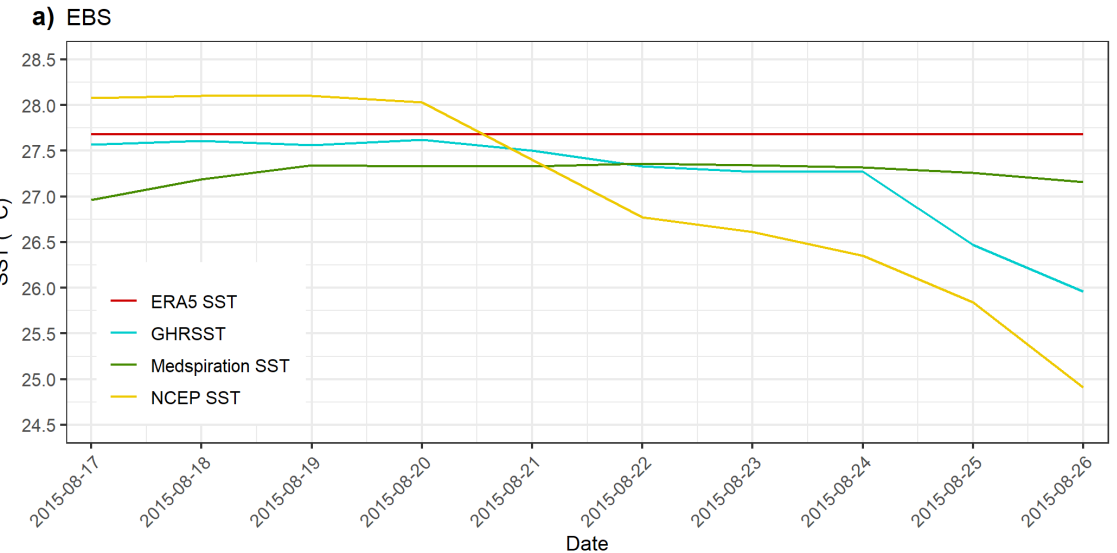

b) MED

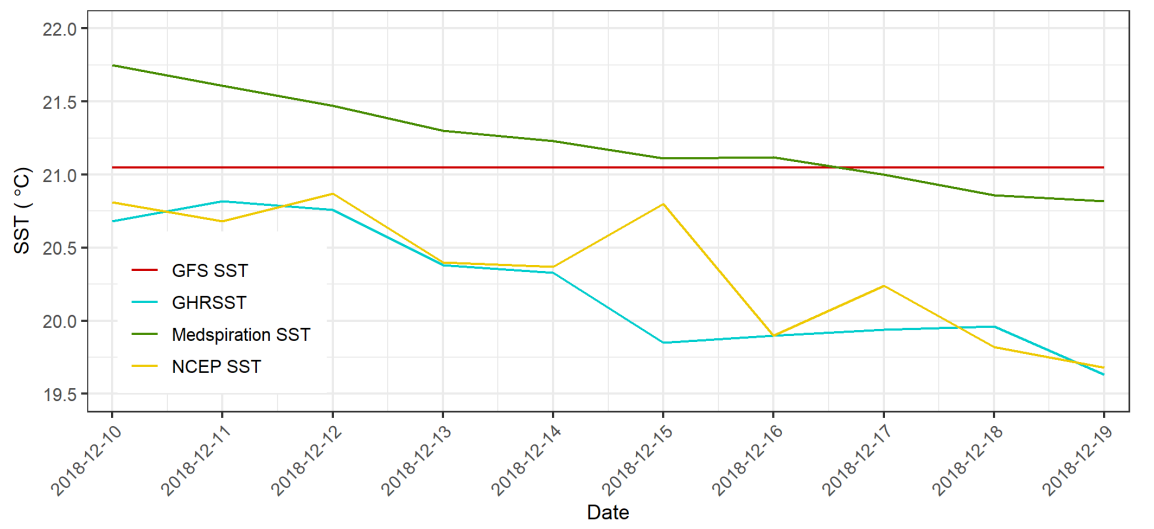



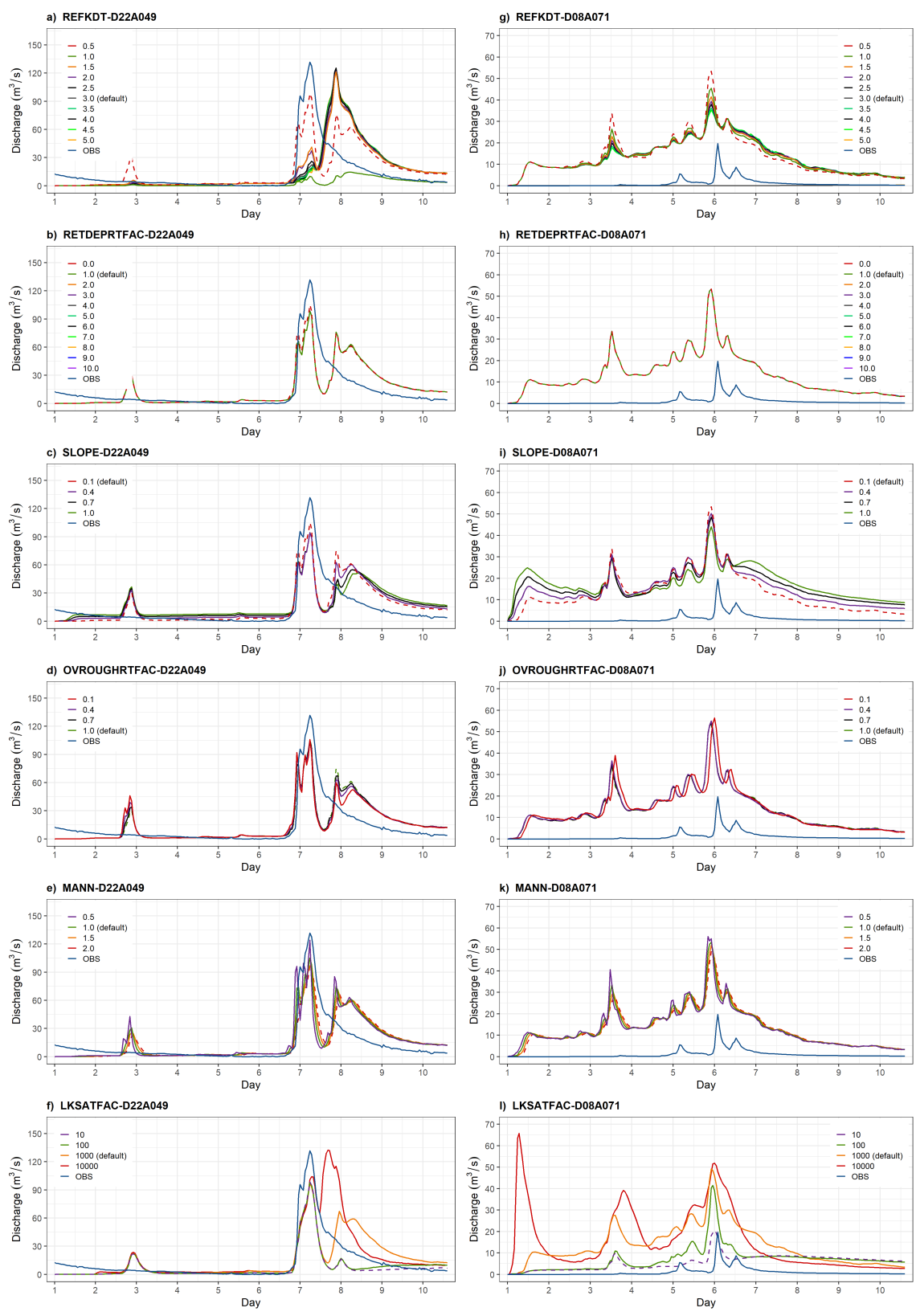
a) $\mathrm{D} 22 \mathrm{~A} 14708 / 17 / 2015-08 / 27 / 2015$

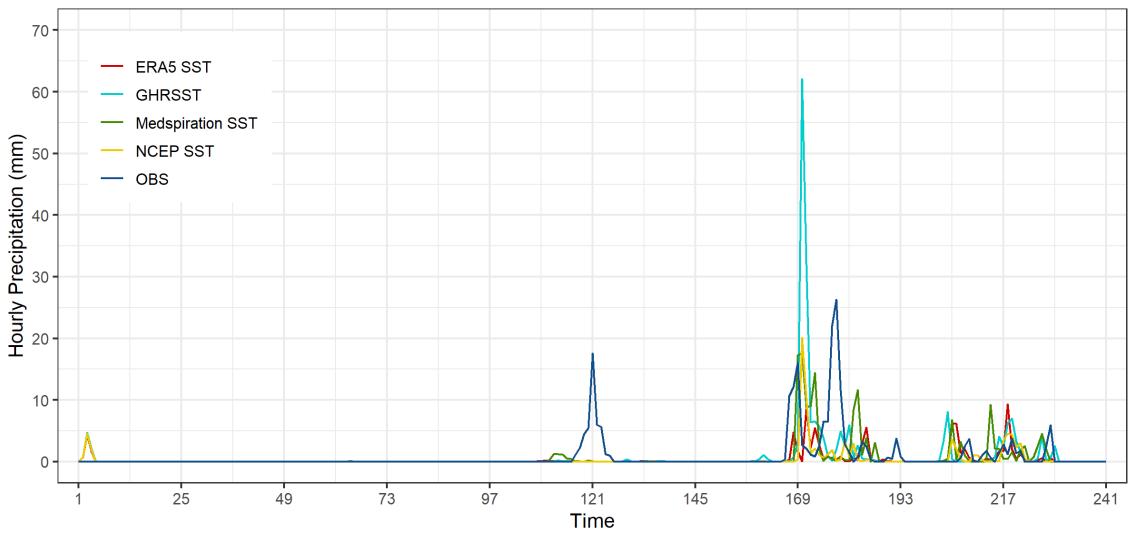

b) $\mathrm{D} 08 \mathrm{~A} 071 \mathrm{12} / 10 / 2018-12 / 20 / 2018$

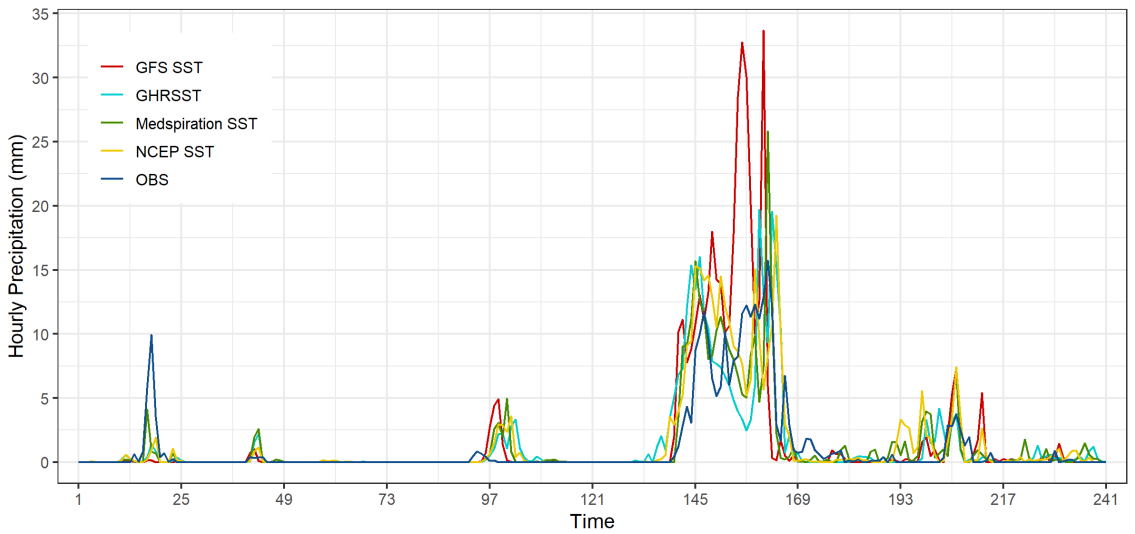



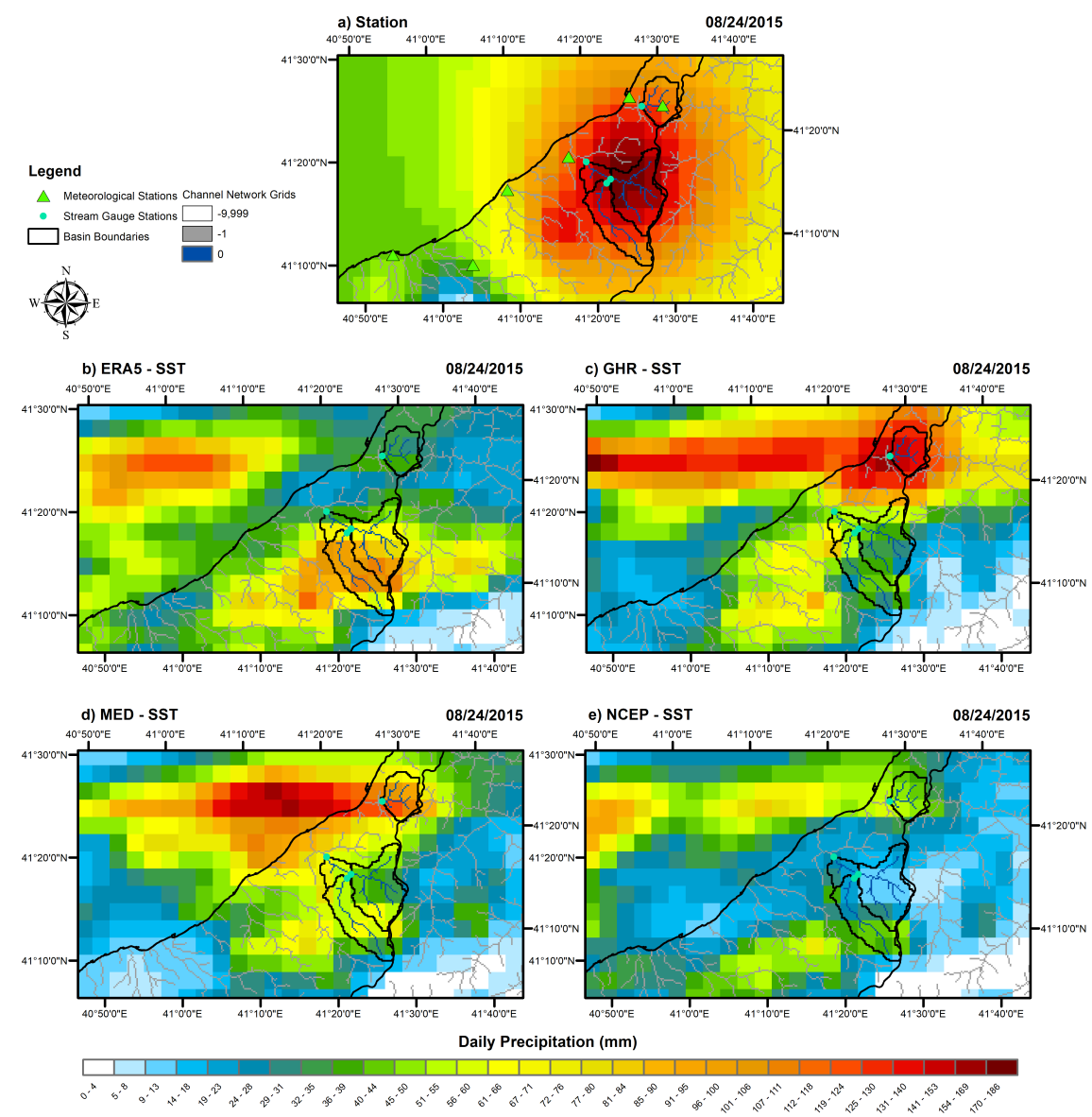

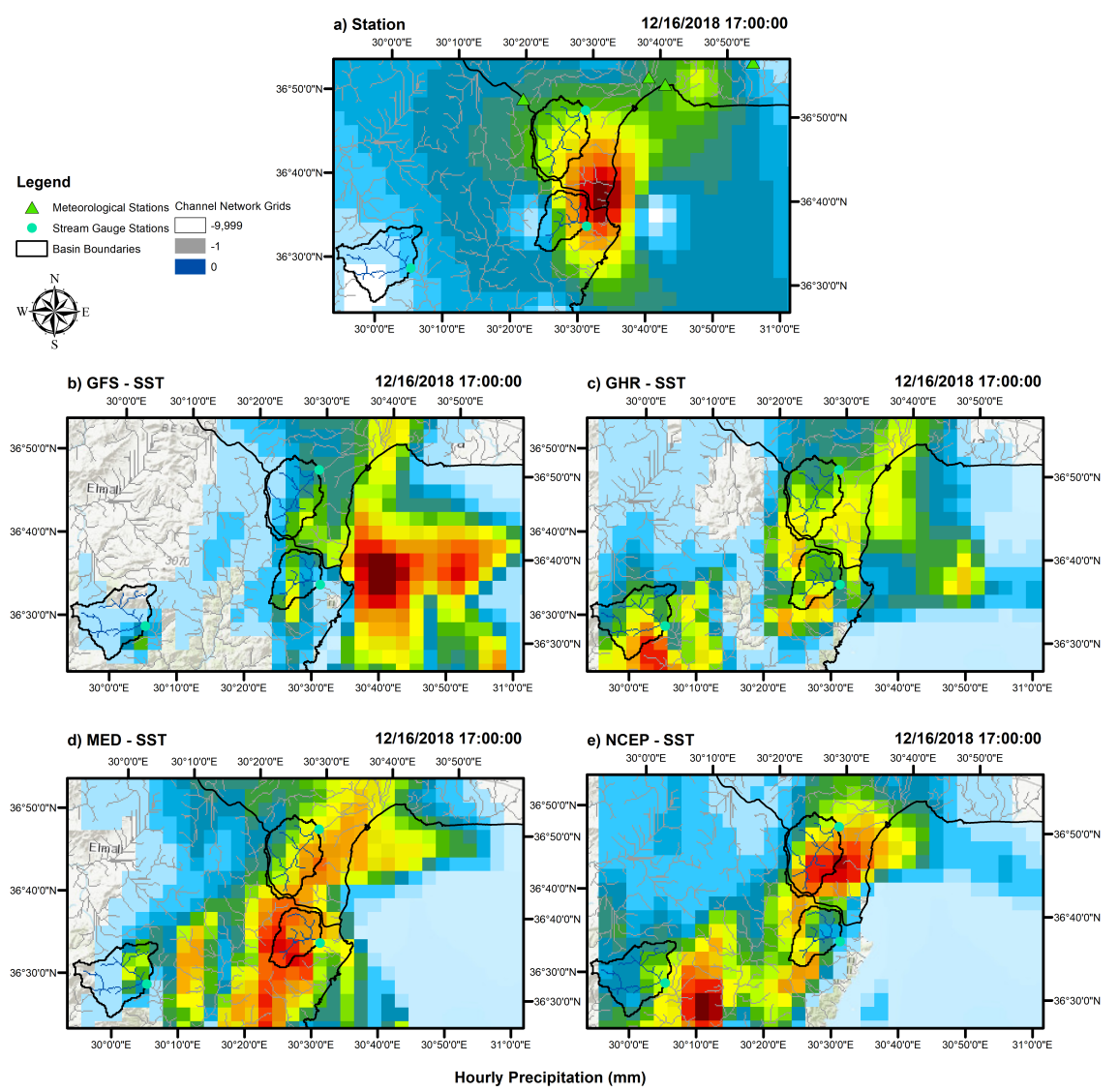

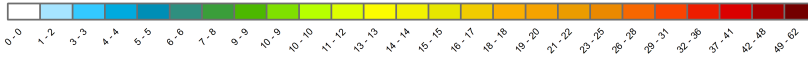



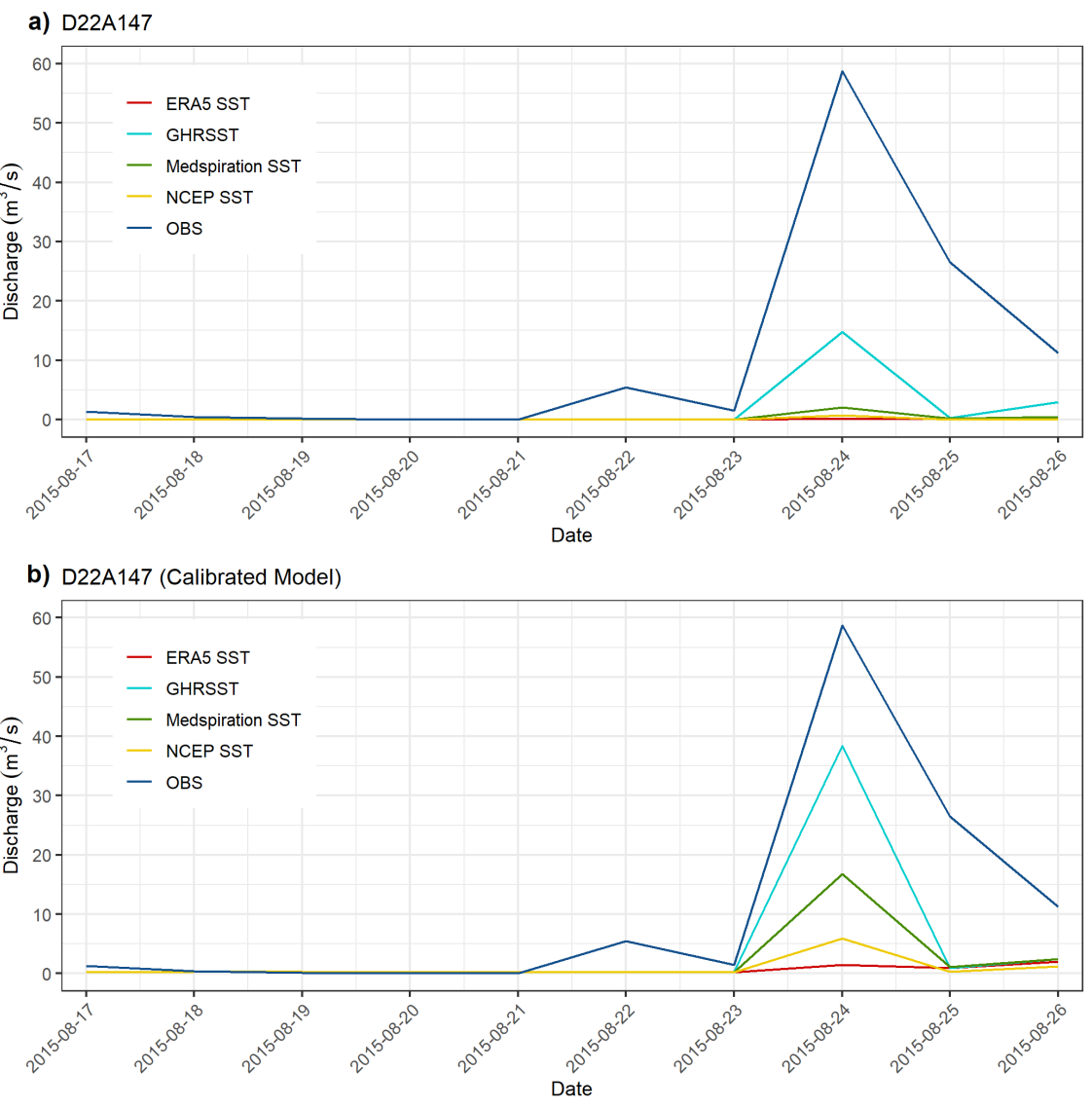


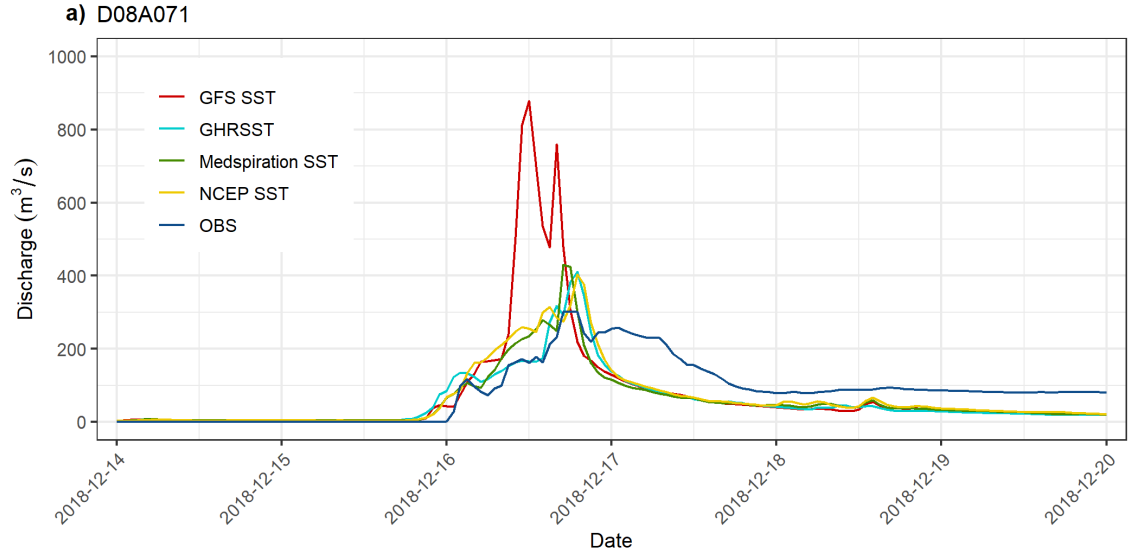

b) D08A071 (Calibrated Model)

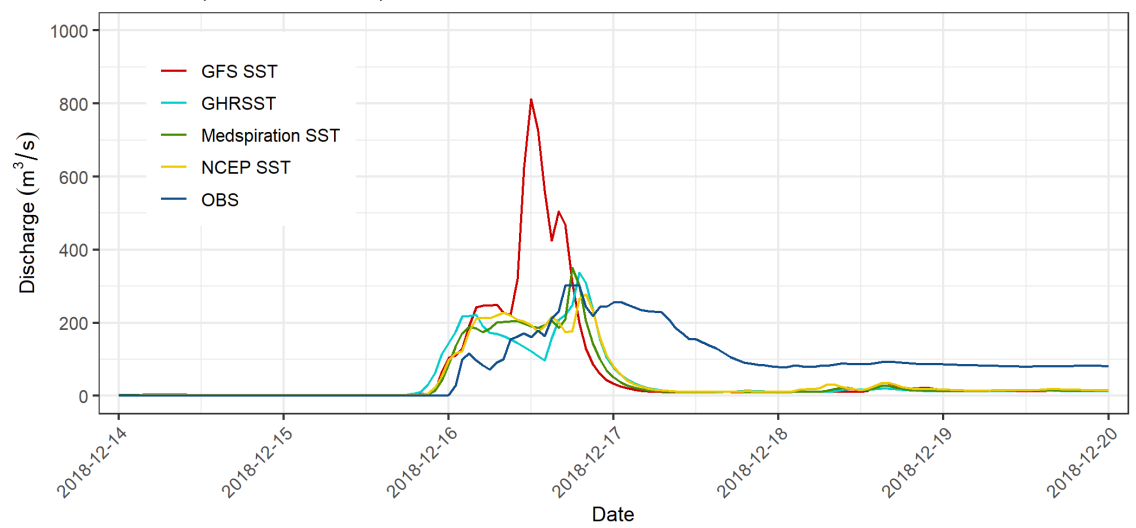



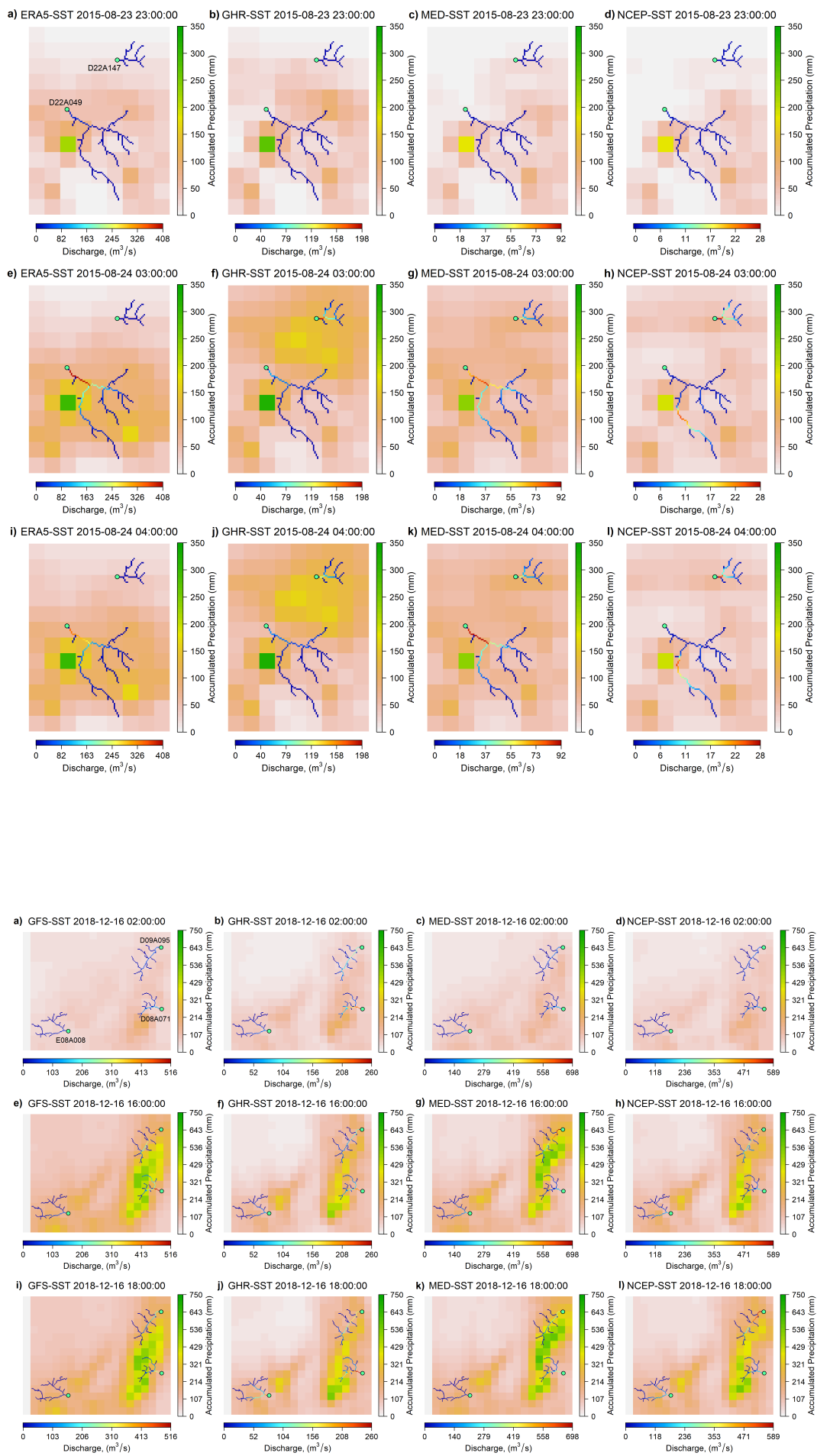